\title{
High Resolution Nuclear Magnetic Resonance: From Chemical Structure to Food Authenticity
}

\author{
By Luisa Mannina ${ }^{1,2}$ and Annalaura Segre ${ }^{2}$ \\ ${ }^{1}$ Università degli Studi del Molise, Facoltà di Scienze Matematiche, Fisiche e Naturali, \\ Via Mazzini 8, 86170 Isernia, Italy \\ ${ }^{2}$ Istituto di Chimica Nucleare (CNR) 00016 Monterotondo Stazione, Roma, Italy
}

\section{CONTENTS}

1. Introduction

2. Practical aspects of the NMR technique
2.1. Sample preparation
2.2. Acquisition time
2.3. Relaxation delay
2.4. Dynamic range
2.5. Detection limits and digital resolution
2.6. Signal Assignment
2.6.1. Standard measurable parameter
2.6.2. ${ }^{1} \mathrm{H}$ Spectral assignment
2.6.3. ${ }^{13} \mathrm{C}$ Spectral assignment
2.7. Quantitative NMR
2.7.1. Use of ${ }^{13} \mathrm{C}$ satellites as internal standard
2.7.2. Data preparation for multivariate analysis

3. Olive oil purity and chemical quantification

3.1. NMR sample preparation and data preparation for statistical analysis.

3.1.1. Sample preparation

3.1.2. Baseline correction and normalization

3.2. Free acidity

3.3. Fatty acid profile

3.4. Unsaturated Fatty acids

3.5. Sterols analysis

3.6. Determination of squalene, cyclo-arthenol and Mgdepleted Chlorophyll.

3.6.1. Squalene

3.6.2. Cyclo-arthenol

3.6.3. Chlorophyll

4. Olive oil sensory quality

5. Olive oil characterization

6. Authentication of olive oil

NMR Glossary

References

\section{RESUMEN}

Resonancia magnética nuclear de alta resolución: De la estructura química a la autentificación de alimentos.

La resonancia magnética nuclear (RMN) es una técnica poderosa capaz de generar una contribución relevante en análisis de alimentos. En esta revisión, se describen algunos aspectos prácticos de la técnica (preparación de la muestra, tiempo de adquisición, retraso en la relajación, etc) junto con algunos métodos espectrales de asignación del espectro (técnicas selectivas 2D y 1D). También se describen algunos ejemplos del análisis cuantitativo. En particular, se discuten los resultados relativos al estudio RMN de los aceites de oliva, entre estos: la comparación entre los análisis convencionales y los análisis por RMN en la caracterización del aceite de oliva; la determinación de componentes menores del aceite de oliva, como el escualeno, cicloartenol y clorofilas; el panel sensorial y su relación con los datos de RMN; y la caracterización geográfica de los aceites de oliva.
PALABRAS-CLAVE: Aceite de oliva - Análisis de alimentos Análisis estadístico - RMN.

\section{SUMMARY}

High resolution nuclear magnetic resonance: From chemical structure to food authenticity.

Nuclear magnetic resonance (NMR) is a powerful technique able to give us a relevant contribution in food analysis. In this review, some practical aspects of this technique (sample preparation, acquisition time, relaxation delay, etc) as well as some methods of spectral assignment of the spectra (2D and $1 \mathrm{D}$ selective technique) are reported. Some examples of NMR quantitative analyses are reported. In particular, the results relative to the NMR study of olive oils are discussed, among these: the comparison between conventional analyses and the NMR analysis in the olive oil characterization; the NMR determination of minor components such as squalene, cyclo-arthenol and chlorophyll in olive oil; the panel test and its relationship with NMR data; the geographical characterization of olive oils.

KEY-WORDS: Food analysis - NMR - Olive oil - Statistical analysis.

\section{INTRODUCTION}

Nuclear Magnetic Resonance (NMR) is a branch of spectroscopy based on the fact that most atomic nuclei oriented by a strong magnetic field absorb radiation at characteristic frequencies. The parameters that can be measured on the resulting spectral lines (line positions, intensities, line widths, multiplicities and transients in time-dependent experiments) can be interpreted in terms of molecular structure, conformation, molecular motion and other rate processes. The usefulness of NMR to the chemist stems in large measure from the finding that any given isotope $\left({ }^{1} \mathrm{H},{ }^{13} \mathrm{C},{ }^{31} \mathrm{P} \ldots.\right)$ in different chemical environments gives rise to distinct chemically shifted spectral lines. Therefore, it is possible to observe a specific isotope even in complex structures, both in solution and in the solid state. Different NMR experiments and equipment give different information. This information can be obtained using high resolution NMR, low resolution NMR and M.R. imaging. High resolution NMR allows performing qualitative and quantitative analysis of samples in solution, to determine the structure of molecules in solution and of 
molecules in solid state and/or semi-solid state in Magic Angle Spinning condition. Pulsed low resolution NMR gives information about the relaxation times, the intra and inter molecular motions, diffusion processes, dynamic, thermodynamic and structural properties of liquids in porous systems, phase transitions. Moreover, pulsed low-resolution NMR methods allow obtaining the measure of free and bound water in materials and in food. Magnetic Resonance Imaging gives a bi or three-dimensional picture of tissues using suitable NMR parameters for the contrast; these are the spin density, the relaxation times, and eventually the diffusion coefficients.

All these NMR techniques can be useful in the characterization of food. However, to assess the role of NMR in food chemistry we must know the specific problem it has to solve, how conclusive the evidence can be that derives from it, and how it compares to other methods that can be brought to bear on the same problems. In literature many NMR studies have been reported on different type of food such as wine, olive oil, coffee, fruit juices, milk, meat, egg, starch granules, flour, etc) using different NMR techniques. The aim of this monograph is to discuss the contributions of high resolution NMR to food analysis and in particular to describe the NMR method used in the study of olive oil.

\section{PRACTICAL ASPECTS OF THE NMR TECHNIQUE}

\subsection{Sample preparation}

In order to obtain a good NMR spectrum of a given compound, a thorough preparation of the sample is essential. Tubes must be cleaned properly; solvents have to be stored and handled carefully in order to avoid contamination. It is important to avoid the presence of paramagnetic contaminants; in fact, these compounds cause a strong line broadening and loss of resolution.

The choice of the solvent is critical. When NMR spectra are obtained in solution, a suitable solvent must be chosen, ensuring a long-term stable solution. Sometimes, in order to obtain a complete dissolution of the sample, it is worth the use of mixed solvents (Sacchi et al. 1996). Great attention must be paid to the dissolution procedure and timing; in fact, whereas in most organic compounds full dissolution occurs in a few seconds, other compounds such as fats require longer times to ensure a perfect and stable dissolution. Therefore, it is a good laboratory norm to wait for a few days until the sample is perfectly stable.

\subsection{Acquisition time}

The length of time spent in sampling is referred to as the acquisition time. The total acquisition time for a single FID depends on the spectral width and on the number of data points collected. The digital resolution is the reciprocal of the acquisition time. It must be noted that for most spectra in solution the time necessary to collect a single run (scan) might be rather long. This is particularly true for ${ }^{13} \mathrm{C}$ spectra since lines are rather narrow, i.e. a high digital resolution is necessary, whereas the spectral range is rather large approximately $200 \mathrm{ppm}$. This means that, in a single scan, acquisition times of approximately $10 \mathrm{~s}$ are essential.

\subsection{Relaxation delay}

In order to avoid saturation of the NMR signals careful attention must be paid to the relaxation delay. In a multi-scan procedure relaxation delay is the delay between two consecutive scans. It must be chosen in such a way that the total time between two scans (acquisition time plus relaxation delay) is enough for a return of nuclear spins to their ground state. A full treatment of relaxation delays was given by Ernst et al. (1987). The above observations are mostly relevant in the presence of quaternary $\mathrm{C}$ atoms, or $\mathrm{C}=\mathrm{O}$ groups in ${ }^{13} \mathrm{C}$ spectra; relaxation delays as long as $30-40 \mathrm{~s}$ sometimes must be chosen.

\subsection{Dynamic range}

The electrical NMR signal must be converted into digital form prior to perform a numerical Fourier transform: the electrical signal must be converted into a stream of numbers. A critical problem in the digitization process is the amplitude of the signals. The problem is the manner in which these numbers can be represented and stored. The analogue-todigital converter (ADC) samples a voltage and gives as an output a binary number proportional to it. The important factors influencing this process are the number of bits the ADC uses to represent the signal voltage and the number of bits in a single word of the computer memory (typical word lengths for NMR are 12-16 bits). It is advantageous for the ADC to represent the signal with the largest possible number of bits. If the range of signal amplitude is represented using 12 bits, the dynamic range available with the 12 bits digitiser is about 2000:1. The NMR signal must fit into the digitiser otherwise a problem of distortions can arise. On the other hand, if the biggest signal fills perfectly the ADC, a signal more than 2000 times smaller cannot be detected. This means that the digitiser cannot accurately handle signals, which are extremely weak compared to the strongest signals. In modern spectrometers, however, the dynamic range obtained is always higher than $10^{5}$. 


\subsection{Detection limits and Digital Resolution}

Diode detectors of the sort used in radios cannot be used in NMR due to their intrinsic non-linearity. Moreover, a detector that is only sensitive to the signal amplitude cannot cope with a signal buried in noise because the output is then mainly determined by the noise that has a non-zero average amplitude (zero-offset). Analogical phase sensitive detectors are nowadays linear over a wide range of signal size. Fully digital instruments are also available which increase the sensitivity without introducing any phase distortion.

The obtainable accuracy of an NMR spectrum is given by the used memory. In the NMR spectrum if the memory size is $\mathrm{SI}, \mathrm{SI} / 2$ imaginary and $\mathrm{SI} / 2$ real points are present. The digital resolution DR, i.e. the frequency separation between data points, is usually calculated as $\mathrm{DR}=2 \mathrm{SW} / \mathrm{SI}$ (SW = Spectral Width). Digital resolution, acquisition time, dwell time and spectral width are correlated; in fact, the digital resolution can be expressed as the reciprocal of the acquisition time. When performing an NMR experiment, it is important to decide the necessary resolution, the acquisition time has to be the reciprocal of resolution. In order to increase the digital resolution, you can either increase the SI or decrease the spectral width.

\subsection{Signal Assignment}

\subsubsection{Standard measurable parameter}

The basic information observable in NMR is simply a spectral line characterized by its intensity (and sometimes line-width) and its spectral position (the spectral frequency). The standard measurable parameters of a given $X$ spectral lines are:

- The centre of line: it refers to a standard line and is called chemical shift and it is usually given in $\mathrm{ppm}(\mathrm{ppm}=\mathrm{X}$ frequency - Standard

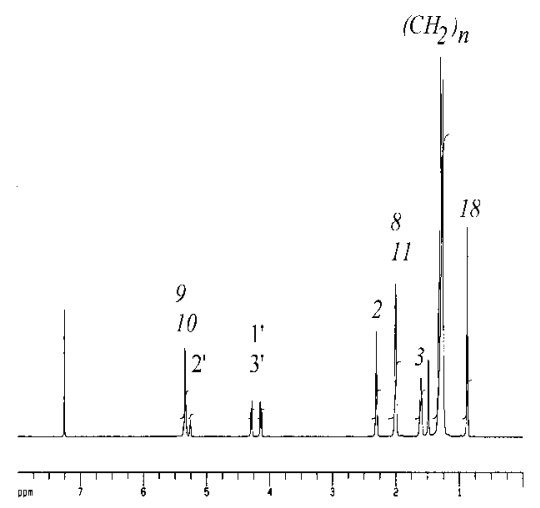

Figure 1

${ }^{1} \mathrm{H}$ NMR spectrum at $600.13 \mathrm{MHz}$ of triolein in $\mathrm{CDCl}_{3}$, at $300 \mathrm{~K}$. Peaks are reported in Scheme 1.

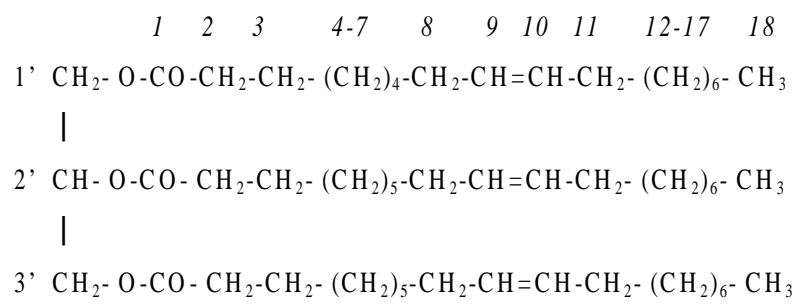

frequency / carrier frequency; all frequencies are given in $\mathrm{Hz}$ ).

- The multiplicity for split lines: it derives from neighbour interactions and it is due to the presence of coupling parameters called coupling constants.

- The line intensity: it is properly measured as the area under the line and reflects accurately the number of nuclei in each environment.

- The line width: it is usually measured at half height of the signal and contains information on rate processes, including the rates of molecular motion (Capitani et al. 1991).

- Line intensities: if measured as transients in time-dependent experiments they give other parameters (dynamic), useful in the physical-chemical characterization of the system.

\subsection{2. ${ }^{1} H$ Spectral assignment}

Some basic features of a ${ }^{1} \mathrm{H}$ NMR spectrum are shown in Figure 1; this is the $600.13 \mathrm{MHz}{ }^{1} \mathrm{H}$ spectrum of triolein (Scheme 1).

The assignment of the spectrum of triolein is discussed in details:

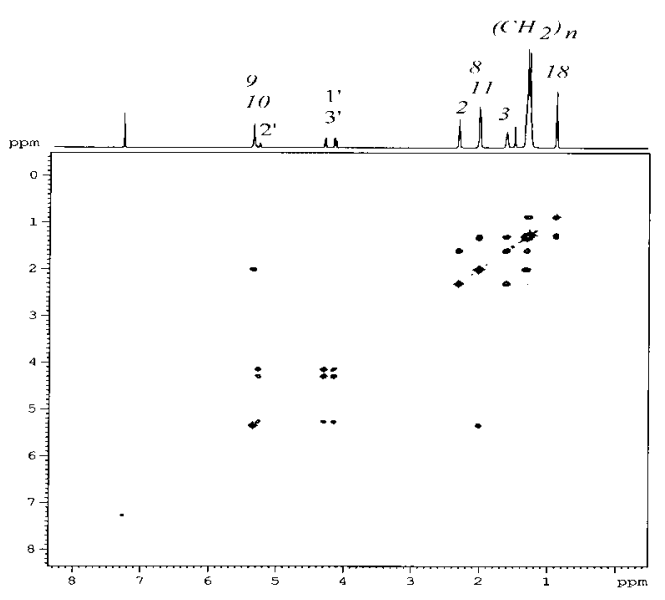

Figure 2

COSY 45 of triolein in $\mathrm{CDCl}_{3}$ at $300 \mathrm{~K}$. At the top ${ }^{1} \mathrm{H}$ spectrum of triolein is reported: labelled peaks are identified as reported in scheme 1. Cross-peaks due to J-coupled protons are marked with a arrow. 
- Glycerol moiety. The CH-2' proton of glycerol gives the complex multiplet at $5.3 \mathrm{ppm}$; the $\mathrm{CH}_{2}-1$ ' and $\mathrm{CH}_{2}-3$ ' give the two quartets at 4.25 $\mathrm{ppm}$ and $4.05 \mathrm{ppm}$ respectively. The different chemical shift of protons belonging to each of these $\mathrm{CH}_{2}$ groups is due to the different position, anti and sin, that they have with respect to the $\mathrm{CH}-2$ '.

- Fatty chain: The $\mathrm{CH}_{3}-18$ gives the triplet at 0.8 ppm; the saturated $\left(\mathrm{CH}_{2}\right)_{n}$ groups give the broad resonance at 1.2-1.3 ppm; the $\mathrm{CH}_{2}-2$ group near to the carboxyl gives the multiplet at $2.3 \mathrm{ppm}$; the $\mathrm{CH}_{2}-3$ next neighbour to the carboxyl gives the $1.55 \mathrm{ppm}$ resonance; the allylic $\mathrm{CH}_{2}-8$ and $\mathrm{CH}_{2}-11$ give resonance at $1.98 \mathrm{ppm}$. The $\mathrm{CH}-9$ and $\mathrm{CH}-10$ olefin protons give the complex pattern at $5.2 \mathrm{ppm}$.

It is important to note that the line intensities (integrals) of the signals are strictly proportional to the number of protons present in each functional group.

This assignment can be easily performed using 2D methods (see NMR Glossary). In Figure 2 shows a 2D COSY map of triolein in $\mathrm{CDCl}_{3}$. Neighbouring groups ( $J$ coupled) give rise to cross-peaks in this map. For example, the $\mathrm{CH}_{3}-18$ at $0.8 \mathrm{ppm}$ gives a cross peak with the neighbouring $\mathrm{CH}_{2}$ group; the $\mathrm{CH}-2$ group of the glycerol moiety gives cross-peaks with the neighbouring $\mathrm{CH}_{2}-1$ and $\mathrm{CH}_{2}-3$ groups. From all these observed cross-peaks the previously given spectral assignment is univocally obtained.

\subsection{3. ${ }^{13} \mathrm{C}$ Spectral assignment}

${ }^{13} \mathrm{C}$ spectrum gives important information about the structure, and the major components of any sample. The assignment of a ${ }^{13} \mathrm{C}$ spectrum can be obtained using different $2 \mathrm{D}$ and $1 \mathrm{D}$ selective experiments. Mannina et al. (1999a, 2000) have reported the method to carry out the full assignment of the ${ }^{13} \mathrm{C}$ spectrum of triolein. This method needs to carry out the following acquisition experiments:

${ }^{13} \mathrm{C}$ spectrum of the sample. Figure 3 shows all ${ }^{13} \mathrm{C}$ signals of the triolein.

${ }^{1} \mathrm{H}$ spectrum of the sample. Figure 1 shows all ${ }^{1} \mathrm{H}$ signals of the triolein.

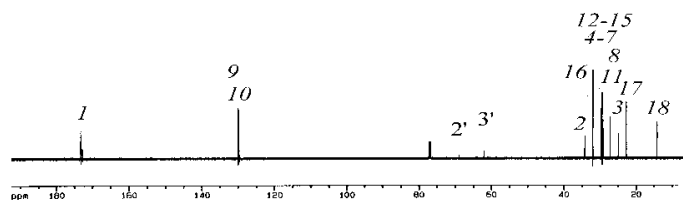

Figure 3

${ }^{13} \mathrm{C}$ spectrum of triolein $(100 \mu \mathrm{L})$ in $\mathrm{CDCl} 3(600 \mu \mathrm{L})$ at $300 \mathrm{~K}$. Peaks are reported in Scheme 1.
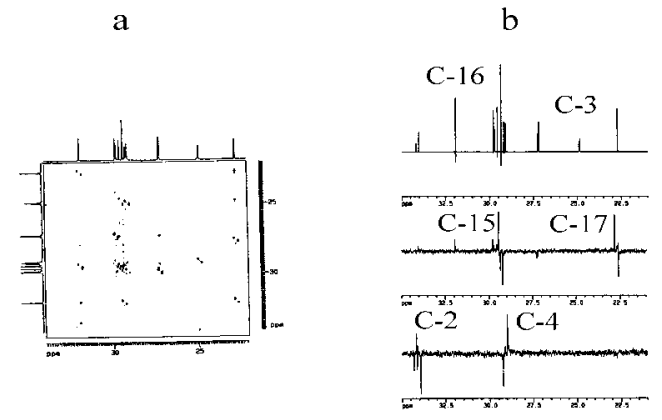

Figure 4

(a) 2D INADEQUATE spectrum of triolein relative to the spectral range 22.0-34.0 ppm. (b) Top trace: ${ }^{13} \mathrm{C}$ spectrum in the 22.0-34.0 ppm range. Middle trace: $1 \mathrm{D}$ selective INADEQUATE experiment obtained by selective irradiation of $\mathrm{C}-16$. Bottom trace: 1D selective INADEQUATE experiment obtained by selective irradiation of $\mathrm{C}-3$.

2D heterocorrelated experiment (Braun et al. 1998). This experiment allows correlating the ${ }^{1} \mathrm{H}$ and ${ }^{13} \mathrm{C}$ spectra. ${ }^{13} \mathrm{C}$ spectrum is easily assigned if the proton spectrum is fully assigned and well resolved. The ${ }^{1} \mathrm{H}$ spectral range is quite small in the case of triolein, about 10-12 ppm, which produces a wide overlap of the signals. But the ${ }^{13} \mathrm{C}$ spectral range is, on the contrary, larger than $200 \mathrm{ppm}$ and shows a complete resolution of all resonances. Figure 3 shows that, in the case of triolein, the heterocorrelated experiment allows to assign easily only those peaks whose ${ }^{1} \mathrm{H}$ resonance are well resolved; e.g., C-2', $\mathrm{C} 9, \mathrm{C} 10, \mathrm{CH}_{2}-17$ and $\mathrm{CH}_{3}-18$.

2D INADEQUATE experiment. This experiment, cumbersome and very insensitive, is however able to connect the resonances of nearby $\mathrm{C}$ atoms. This

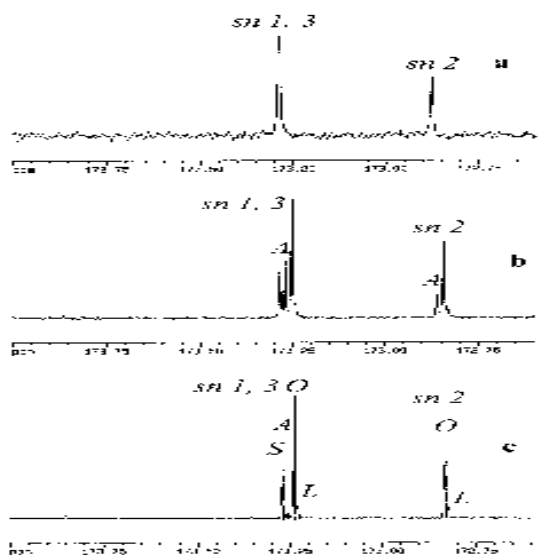

Figure 5

Expansion of the carbonyl region in the ${ }^{13} \mathrm{C}$ spectra of (a) 11-vaccenic tri-ester, (b) olive oil + 11-vaccenic tri-ester, (c) olive oil.

Note. S, Tripalmitin and tristearin; O, Triolein; A, trivaccenic fatty chain; $\mathrm{L}$, trilinolein; sn 1,3 and $s n 2$ are the positions 1,3 and 2 on the glycerol moiety. 
experiment allows us to obtain ${ }^{13} \mathrm{C}$ assignment when two ${ }^{13} \mathrm{C}$ resonances are separated enough as to be resolved by $2 \mathrm{D}$ experiments. In the case of triolein, Figure 4, C-18 is connected to $\mathrm{C}-17, \mathrm{C} 17$ is connected to $\mathrm{C} 18$ and $\mathrm{C} 16$ and so on. However, this experiment has not enough resolution to assign the whole spectrum if the ${ }^{13} \mathrm{C}$ signals are not well separated. This is the case of the very crowded, spectral region of triolein (28-30ppm) showed in Figure 3. 1D selective experiment has to be performed to assign this spectral region.

1D selective INADEQUATE experiment. One resonance at a time is excited in this experiment. The resonance due to nearby carbons, and only those, will appear as antiphase doublets. In the case of triolein, the selective excitation of $\mathrm{C}-16$ gives rise to two signals due to its neighbouring carbons (i.e. C-15 and $\mathrm{C}-17$ ) while the selective excitation of $\mathrm{C}-3$ gives rise to two signals due to $\mathrm{C}-2$ and $\mathrm{C}-4$. This procedure is repeated until a full spectral assignment is obtained.

Using the previously reported procedure, it has been possible to assign the ${ }^{13} \mathrm{C}$ spectrum of many compounds. In particular, it is possible to assign "standard" compounds present in foodstuffs. Some of these standard compounds are the common tri-alkyl esters such as tripalmitin, triolein, trilinolein, tri-11-eicosenoin. The assignment of these standard compounds can be useful to analyse admixtures of vegetable oils (Mannina et al. 1999a). However, the value of the chemical shifts of the standard compounds is not always enough to assign the spectrum of the admixtures; in fact, the values of chemical shifts depend son the concentration of the single compound in the admixture (Mannina et al. 2000). The method of the standard addition do has to be then used in order to assign correctly the standard compounds present in the admixtures. This classical method requires the acquisition of three spectra: (i) the spectrum of the sample; (ii) the spectrum of the standard compound; and (iii) the spectrum of the sample + standard compound. This method has been used (Mannina et al. 1999a) for the full assignment of the olive oil ${ }^{13} \mathrm{C}$ spectrum by adding small amounts of cited tri-alkyl esters to olive oils (Figure 5).

\subsection{Quantitative NMR}

\subsubsection{Use of ${ }^{13} \mathrm{C}$ satellites as internal standard}

The ${ }^{13} \mathrm{C}$ isotope has spin $1 / 2$ and a natural abundance of about $1.108 \%$. The presence of this isotope in all organic compound can be very useful for the NMR quantitative analysis; in fact, the presence of one bond coupling constant (at least $130 \mathrm{~Hz}$ ) causes a strong splitting of each ${ }^{1} \mathrm{H}$ line due to a proton bound to ${ }^{13} \mathrm{C}$ carbon atom originating the so called satellite lines which constitute a perfect internal standard.

\subsubsection{Data preparation for multivariate analysis}

The base line correction is always suggested to perform accurate measurements. This correction is however absolutely necessary in the case of ${ }^{1} \mathrm{H}$ spectra if a large number of scans is performed. In fact, the empty probe itself, and the system as a whole, can produce a large hump in the real spectrum. There are suitable mathematical routines for the base line correction in all commercial spectrometers. These routines use polynomial equations which, carrying out the subtraction from the base line, act as perfect flatteners without producing any appreciable error. This means that more sophisticated functions are not usually necessary. After performing the base line correction, the normalization must be done by selecting the height value of a particular resonance. The choice of this normalizing resonance is not trivial since it must be inside a neat delimited range, it must be insensitive to composition, acidity, and possible defects. In the case of an admixture, the intensity of ${ }^{1} \mathrm{H}$-NMR resonances is proportional to the number of protons belonging to a given peak multiplied by the molar concentration, i.e. the number of equivalent protons.

\section{OLIVE OIL PURITY AND CHEMICAL QUANTIFICATION}

\subsection{NMR sample preparation and data preparation for statistical analysis}

\subsubsection{Sample preparation}

In the case of olive oils, the use of the admixture chloroform/dimethyl sulfoxide $(700 \mu \mathrm{L} \mathrm{CDCl} 3+20 \mu \mathrm{L}$ DMSO $d_{6}$ ), in its suitable proportions, ensures a
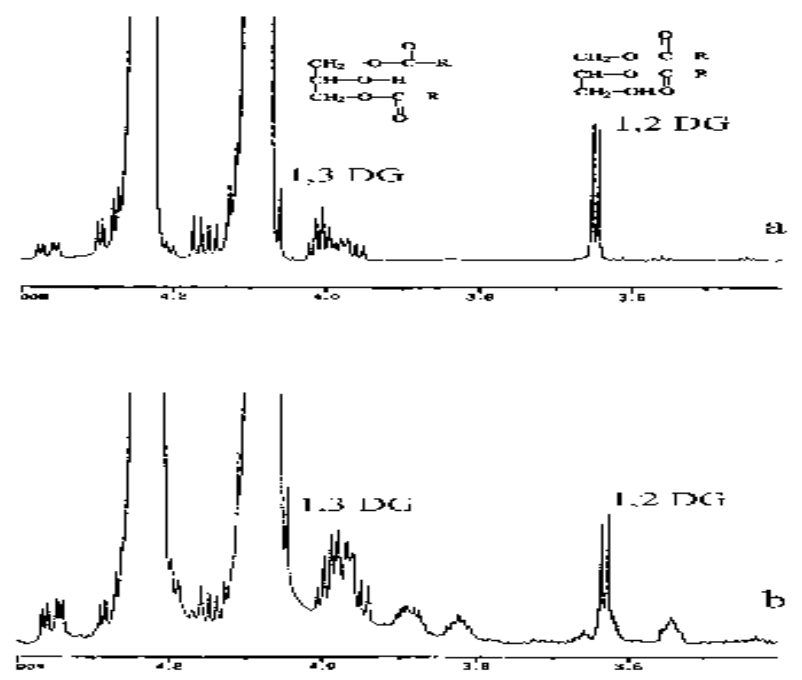

Figure 6

Expansion of the 3.4 - 4.4 ppm proton spectral region. 1,2 and 1,3 diglyceride resonances are shown. (A) extra-virgin olive oil, and (B) lampante virgin olive oil. 
good stability and the perfect dissolution of almost all the oil components. The polyphenols are a noticeable exception because they are fully insoluble in the cited admixture. Therefore, the presence of NMR signals in the 7.3ppm - 8ppm region is always indicative of the presence of low molecular weight phenols (tyrosol, hydroxy-tyrosol, etc.). These signals are associated with a bad separation of the oil from the watery fraction, or they are related with defects in the extraction procedure.

\subsubsection{Base line correction and normalization}

In the case of olive oil, it is necessary to perform a careful base line correction and to normalize the spectrum choosing a suitable resonance. A perfect choice is a resonance at $1.61 \mathrm{ppm}$ due to $\mathrm{CH}_{2}$ of saturated chains. If the intensity of this resonance is set to 1000 , all major resonances will turn normalized in proton equivalents.

\subsection{Free acidity}

The European Community regulation (2568) requires many different analyses for the analytical definition of olive oil quality. The free acidity is one of the best-known conventional analyses (Balestrieri and Marini 1996). Although the ${ }^{1} \mathrm{H}$ NMR spectrum of an olive oil in $\mathrm{CDCl}_{3} / \mathrm{DMSO}$ does not allow obtaining this information directly, it is possible to have an indirect measurement of acidity using the measurable amount of diglycerides. The ${ }^{1} \mathrm{H}$ NMR spectrum (Figure 6) shows the resonances of $s n 1,2$ and sn 1,3 diglycerides at $3.639 \mathrm{ppm}$ and $3.994 \mathrm{ppm}$ respectively (Sacchi et al. 1996). The total profile of diglycerols and their $1,2 / 1,3$ ratio are strongly related to the good quality and freshness and olive oils. In
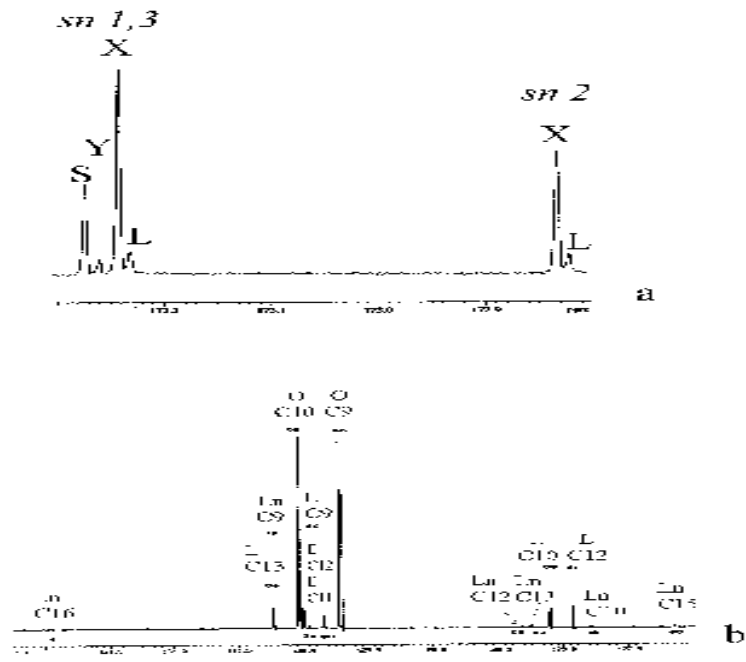

Figure 7

Expansion of (a) carbonyl region (b) ${ }^{13} \mathrm{C}$ double bonds region of an extra virgin olive oil.

Note. S, saturated chains; $Y$, eicosenoic and vaccenic chains; $X$, oleic chain; L, linoleic chain; $\mathrm{O}$, oleic chain; $\mathrm{E}$, eicosenoic and vaccenic chains; $L$, linoleic chain; $L n$, linolenic chain. fact, ${ }^{1} \mathrm{H}$ NMR spectra of lampante olive oils show a much higher amount of total diglycerols than the spectra of extra virgin olive oils. Figures $6 a-b$ corroborate this assertion.

\subsection{Fatty acid profile}

Another important conventional analysis is the determination of fatty acid profile that is usually obtained by gas-chromatographic analysis. The GC allows obtaining the amount of each fatty acid present in olive oil. The typical chromatogram which gives the fatty acid composition (e.g. C14:0, C16, C16-1, C17, C17:1, C18, C18:1, C18:2, C18-3, C20, C20:1, C22-0, C24:0) cannot be performed using ${ }^{1} \mathrm{H}$ NMR. Due to the overlap of signals, ${ }^{1} H$ NMR spectrum allows to distinguish only classes of fatty acids, i.e. fatty acids with $0,1,2$, or 3 double bonds (Sacchi et al. 1996). However, important information on the fatty acid profile can be obtained by ${ }^{13} \mathrm{C}$ NMR (Mannina et al. 1999a). Figure 7 shows, for example, two groups of resonances of the ${ }^{13} \mathrm{C}$ NMR carbonyl region. One group is due to the fatty chains in position 1,3 of the glycerol moiety while the other group is due to fatty acids in position 2 .

In olive oil and inside the first group, there are interesting resonances: (i) the resonance at 173.27 ppm is due to C14:0, C16, C18, C20 and C22; (ii) the resonance at $173.26 \mathrm{ppm}$ is due to eicosenoic and vaccenic acids (cis-11-octadecenoic and cis-11-eicosenoic acids), i.e. due to unsaturated fatty chains with the insaturation in position 11; (iii) the resonance at 173.24 is due to unsaturated fatty chains with the insaturation in position $9, \mathrm{C} 18: 1$ and C16:1 (the oleic acid is the most abundant in olive oil); (iv) the resonance at $173.23 \mathrm{ppm}$ is due to linoleic acid only. Finally, the resonance of C18:3 linolenic acid is usually too weak to be observed and hence the total amount of $\mathrm{C} 18: 3$ must be measured on the ${ }^{1} \mathrm{H}$ spectrum.

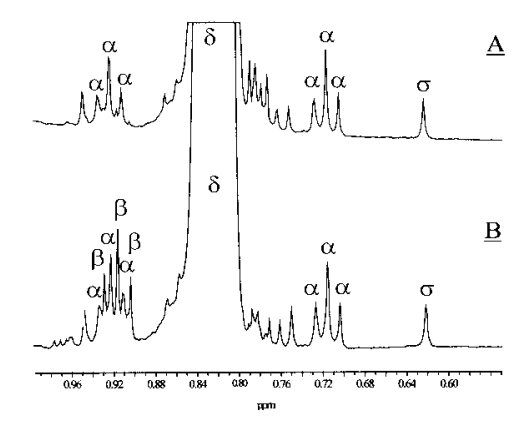

Figure 8

Expansion of the $0.62-1.00 \mathrm{ppm}{ }^{1} \mathrm{H}$ spectral region in: A) hazelnut oil and B) olive oil.

Note. $\alpha{ }^{13} \mathrm{C}$ satellite of the main methyl resonance (d); B, terminal methyl of linolenic chain; $\delta, \mathrm{CH}_{3}-18$ of $B$-sitosterol. 
There is second group of resonances in the $\mathrm{CO}$ region of the ${ }^{13} \mathrm{C}$ spectrum. The resonance between $172.833 \mathrm{ppm}$ and $172.822 \mathrm{ppm}$ is due to $\mathrm{CO}$ in position 2 substituted on the glycerol moiety. In olive oil only these two resonances have been observed, one due to the oleic residue and the other one to linoleic residue in position sn 1,2 of the glycerol. The presence of any other resonance between 172 ppm $-173 \mathrm{ppm}$ is always due to adulteration.

It must be noted that while gas-chromatographic methods give the full composition of fatty chains, no information is given about the fatty chains distribution on glycerol. Thus, GC and ${ }^{13} \mathrm{C}$ NMR are supplementary rather than competitive methods.

\subsection{Unsaturated Fatty acids}

The conventional method used to determine the total degree of unsaturation is the measure of the iodine number (Balestrieri and Marini 1996). The iodine number of unsaturated fatty acid is not a quantitative measure. It is only an empirical number useful to have qualitative information about the total amount of unsaturation. ${ }^{1} \mathrm{H}$ NMR spectrum allows obtaining the quantitative measure of the unsaturation in a quite different way. All resonances due to trans double bonds lie between $5 \mathrm{ppm}-5.2 \mathrm{ppm}$, and they are due to two protons, all methyl resonances, while the three protons lie between $0.85 \mathrm{ppm}-0.95 \mathrm{ppm}$. Thus, the total unsaturation number, in moles, is given by the ratio between the normalized integrals of these two spectral regions. However, we can obtain the full composition, in terms of unsaturated chains as well as their position on the glycerol moiety (Mannina et al. 1999a, 2000), by observing carefully the spectral region 120ppm-130ppm of the ${ }^{13} \mathrm{C}$ spectrum (Figure 8b).

\subsection{Sterols analysis}

The conventional analysis of sterols is performed using gas-chromatographic methods. According to Croasmun and Carlson (1994), the ${ }^{1} \mathrm{H}$ resonance of methyl $\mathrm{CH}_{3}$ in position 18 of sterols always appears in a narrow range, $0.6 \mathrm{ppm}-0.7 \mathrm{ppm}$, that is quite separated from the resonances of fatty chains. It is possible to observe this useful small spectral region, (Figure 7), and get information about the sterolic composition in any vegetable oil.

All the observed peaks inside the spectral range of $0.57 \mathrm{ppm}-0.70 \mathrm{ppm}$ are due to methyl 18 of steroids, and we can interpret the spectrum exactly as it was a chromatogram; i.e. the integral of each line is linearly proportional to the concentration, and this observation is holds for all steroids. In consequence, even considering only the resonance assignment of $\beta$-sitosterol, we can easily compare the observed pattern with the signal at $0.621 \mathrm{ppm}$ due to methyl 18 of $\beta$-sitosterol (Croasmun and
Carlson 1994). On this regard, NMR gives data fully comparable to those obtained using GC with capillary columns.

We can also compare the resonance at 0.621 ppm of $\beta$-sitosterol directly with the nearby resonance of ${ }^{13} \mathrm{C}$ satellites of the methyl of fatty chains; it is shown in the figure with the symbol $\alpha$. In fact, an exact amount of ${ }^{13} \mathrm{C}, 1.06 \%$, is always present for any given ${ }^{12} \mathrm{C}$. This isotope has spin $1 / 2$ and causes a splitting of the proton-associated resonance. It means that NMR has the possibility of comparing weak and strong lines indirectly, using the ${ }^{13} \mathrm{C}$ satellites of strong lines.

Linolenic acid, $\mathrm{C} 18: 3$, has the ${ }^{1} \mathrm{H}$ methyl resonance shown with the symbol $B$ in Figure 7 . Its resonance appears as a 1:2:1 triplet at $0.916 \mathrm{ppm}$, well separated but quite near to the low-field ${ }^{13} \mathrm{C}$ satellite of the methyl of fatty chains, marked in the same figure with the symbol $\delta$. We can compare, once again, weak and strong lines through the use of ${ }^{13} \mathrm{C}$ satellites.

Particularly interesting is the case of the hazelnut oil that lacks almost completely of C18:3 (Figure 7A). The lack of intensity in the C18:3 methyl resonance should be accompany by a careful GC analysis and by an analysis of the ${ }^{13} \mathrm{C}$ NMR spectrum since it might indicate the presence of hazelnut oil in olive oil. When this resonance is too intense, however, seed oil might have been added and a careful analysis should be also performed. Therefore, the C18:3 methyl resonance should be always carefully

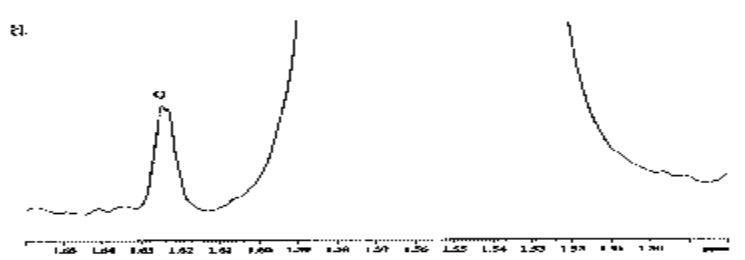

b

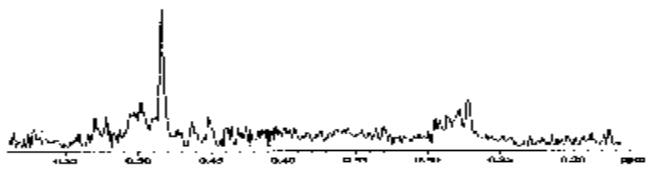

$\mathrm{c}$

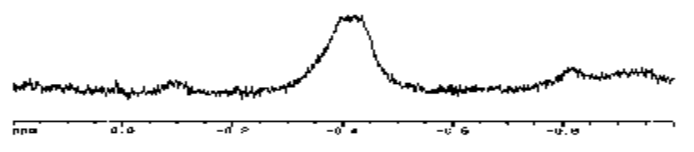

Figure 9

Expansions of ${ }^{1} \mathrm{H}$ spectrum of an olive oil. A) $\mathrm{Q}$, resonance due to squalene; $B$ ) resonance due to cycloartenol; $\mathrm{C}$ ), resonance due to $\mathrm{NH}$ group in the a porphyrin structure of chlorophyll. 
measured since any anomalous value might be symptomatic of adulteration.

In all these measurements, the use of ${ }^{13} \mathrm{C}$ satellites for internal standardization is always recommendable as well as for the measurement of the intensity of olive oil minor components.

\subsection{Determination of squalene, cyclo-arthenol and Mg-depleted Chlorophyll}

\subsubsection{Squalene}

Squalene is always present in olive oils, in amounts of the order of $12.5-75.0 \mathrm{mg} / \mathrm{kg}$ of oil. Its ${ }^{1} \mathrm{H}$ spectrum is quite complex (Pogliani et al. 1994), but a resonance at $1.620 \mathrm{ppm}$ always emerge from the complex spectral pattern of the olive oil, see Figure $9 \mathrm{a}$. The lack of this resonance is always due to full rectification of the sample or to adulteration.

\subsubsection{Cyclo-arthenol}

Cyclo-arthenol is a complex steroid characterised by the presence of a three-member ring. ${ }^{1} \mathrm{H}$ resonances due to cyclo-propanic ring are found at high field in a spectral range completely empty, Figure 9b. Usually not one but two sets of resonances are observed. One set is indeed due to

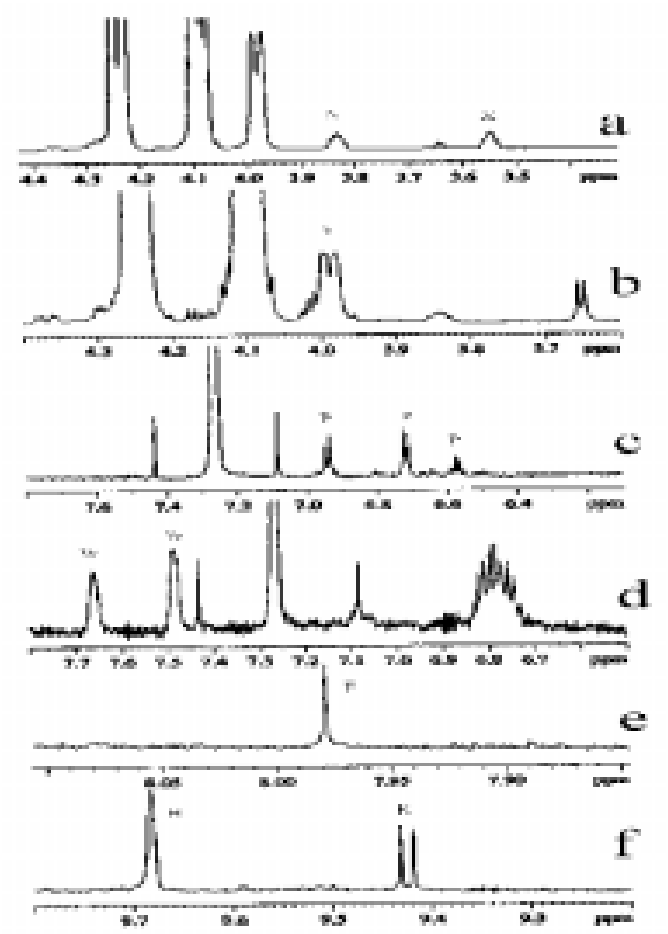

Figure 10

Spectral region of particular olive oils. Characteristic resonances are labelled as: a) $\mathrm{X}$ in bitter olive oil; b) $\mathrm{Y}$ in vinegary tasting olive oil; c) and d) P and W presence of a large amount of phenols due to bad separation from vegetable water;

e) F formaldehyde present in olive oils classified as pungent; f) $\mathrm{K}$ and $\mathrm{H}$ aldehydes in green-fruity olive oil. cyclo-arthenol. We have observed that the other set is due to a transposition of the double bond on the sterol structure. Anyhow the amount of both cyclo-arthenol products can be measured with a very high precision.

\subsubsection{Chlorophyll}

Chlorophyll is sometimes added to improve the green colour of olive oils. In this case, the added product is usually defective, lacking the coordinated magnesium. Thus, a porphyrin structure is present with $\mathrm{NH}$ groups central to the macro-cycle (Sanders and Hunter 1994). In this case, the ${ }^{1} \mathrm{H}$ NMR spectrum of olive oil shows a broad signal at -0.42 ppm (Figure 9c) that means adulteration of the product.

\section{OLIVE OIL SENSORY QUALITY}

Sensory attributes of olive oils are usually evaluated through the so-called panel test. Positive and negative attributes are due to the presence of particular compounds such as polyphenols, aldehydes, terpenes, oxidation products and so on. Some of the products responsible for the particular attributes have been identified and can also be observed and quantified by the ${ }^{1} \mathrm{H}$ spectrum.

Bitter. The bitter tasting of olive oil is due to many different factors such as the presence of leaves in the olives, the presence of unripe drupes and so on. Particular resonances at $3.55 \mathrm{ppm}$ and $3.85 \mathrm{ppm}$ have been found in ${ }^{1} \mathrm{H}$ spectrum of olive oil qualified by their bitterness. Figure 10a shows these peaks.

Vinegary. The vinegary odour is mostly due to the presence of acetic acid whose methyl resonance appears at 3.98 ppm, as it is shown in Figure 10b.

Pungent. This taste is mostly due to polyphenols and alcohols. Furthermore, a high content of formaldehyde has been observed in the ${ }^{1} \mathrm{H}$ spectra of olive oils qualified as pungent. Figure $10 \mathrm{e}$ shows the resonance at $8.00 \mathrm{ppm}$.

Green-fruity. (E)-2-hexenal is one of volatile compounds responsible for the green-fruity odour (Morales et al. 1995). Figure $10 \mathrm{f}$ shows this compound at $9.45 \mathrm{ppm}$.

Undesiderable bitter tasting. The unpleasant bitter tasting is often the result of bad separation of virgin olive oil from vegetable water (defect of sedimentation), Figure $10 \mathrm{~d}$. This defect is always associated to the presence of tyrosol and hydroxy-tyrosol in the ${ }^{1} \mathrm{H}$ spectrum, Figure 10c. As previously mentioned the choice of solvent is particularly important. The use of a mixed solvent $\mathrm{CDCl}_{3} / \mathrm{DMSO}$ offers a particular advantage i.e. polyphenols at high molecular weight are completely insoluble and stay afloat at the top of the sample giving no NMR signal. In the production of olive oil, a wrong procedure, such as an excessive heat of the product, always results in the presence of low 
molecular weight phenols easily observed in the 7.3 ppm - 7.9 ppm spectral range. This spectral range also produces information of a bad separation of the bitter water from the olive oil and other defects in the mashing procedures, Figure 10d. Moreover, the presence of oils deriving from frost olives or infested by worms or flies can give rise to low molecular weight soluble para di-substituted phenols, see Figure 10c.

\section{OLIVE OIL CHARACTERIZATION}

The definition of the geographical origin of extra virgin olive oils is a matter recently introduced. The composition of an extra virgin olive oil is the result of different contributes (Montedoro et al. 1992) such as pedoclimatic effects, cultivar, etc. Therefore, many factors need to be taken into account for a careful definition of the geographical origin based on chemical composition.

The important act of legislation of the Protected Designation of Origin allows the identification of some Mediterranean extra virgin olive oils with the names of the geographical areas where they are produced. This certification increases the value of the Italian, Greek and Spanish products and guarantees a product of high quality and defined origin.

Several attempts have been made to identify the geographical procedence of the olive oil production by means of multivariate analysis of suitable chemical parameters. Principal component analysis (PCA) of fatty acid composition have been used to classify olive oils from different Italian regions (Alessandri et al. 1997; Forina and Tiscornia 1982), and to determine the geographical origin of Greek olive oils by means of their fatty acids and triacylglycerols (Tsimidou et al. 1987). Beyond the statistical analysis, an expert system is used to characterise the geographical origin (olive grown

Table I

Volatile chemical compounds and their ppm with proton NMR

\begin{tabular}{ll}
\hline Compound & ${ }^{1} \mathrm{H}(\mathrm{ppm})$ \\
\hline B-sitosterol & 0.623 \\
Squalene & 1.621 \\
Terpene & 4.530 \\
Terpene & 4.627 \\
Terpene & 4.654 \\
Cycloartenol & 4.881 \\
Formaldehyde & 8.007 \\
Hexanal & 9.705 \\
Branched aldehydes & 9.528 \\
Branched aldehydes & 9.616 \\
Trans-2-hexenal & 9.448 \\
\hline
\end{tabular}

zones and provinces) of Italian, Spanish and Portuguese virgin olive oils by different series of chemical compounds (Aparicio 1988; Aparicio and Alonso 1994; Aparicio et al. 1994,1996).

The combination of high-resolution NMR and statistical analysis gives interesting results for the geographical characterization of olive oils (Mannina et al. 2001a-c). The method requires the ${ }^{1} \mathrm{H}$ NMR spectrum at high field of the olive oils and the intensity measure of a few selected normalized resonances. The NMR resonances are chosen following these criteria:

- The selected resonance must be in an accessible spectral range.

- The signal must be due to a component not related with oxidation or decomposition products.

- The signal should show large intensity variability in different samples.

- The chosen resonances must be independent one another.

Following the above criteria, all fully assigned eleven resonances to a particular compound, have been chosen (Table I).

The following steps of statistical procedures, performed on the intensity of the selected resonances, have been proposed (Mannina et al. 2001b):

1. Analysis of Variance (ANOVA) on the selected resonances.

2. Tree Clustering Analysis (TCA) on eleven selected resonances without any a priori hypothesis.

3. K-means Clustering Analysis (LDA) on the eleven selected resonances with the a priori hypothesis; i.e., the number of place of production on the basis of the tree clustering analysis.

4. Linear Discriminant Analysis (LDA) on the eleven selected resonances with the a priori hypothesis; i.e., the number of places of production on the basis of the tree clustering analysis.

5. Reliability of the system. In order to prove the reliability of the system in further calculation, some samples are randomly selected (Mannina et al. 2001a). If the selected unknown samples are well classified, the system is stable and can be use for real samples.

The statistical processing of the relative weight of the eleven selected resonances allows selecting the most significant ones. Because the variability of the eleven selected resonances depends on the many different factors, such as environment, cultivars, particular defects of the olive oil and the year, it is important to repeat this statistical analysis. This means that the correct resonances must be identified according to the specific problem; i.e. with there is high discriminating power. For instance a resonance due to a specific compound may be important in the discrimination of between European 

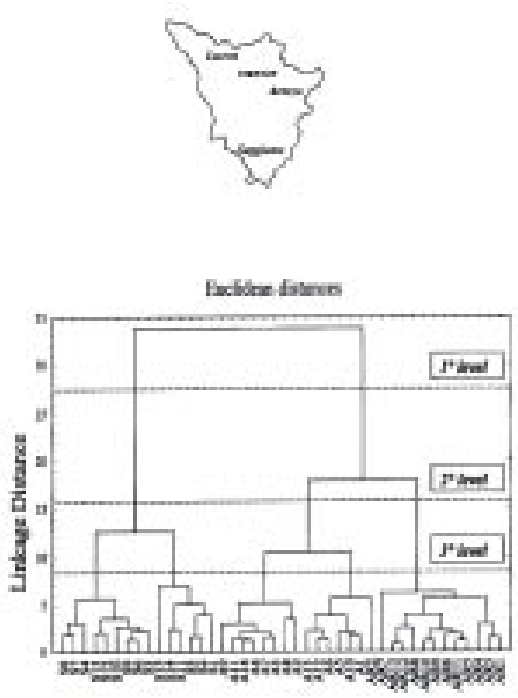

Figure 11

Tree Clustering Analysis of olive oils from different districts of Tuscany.

Note. Samples labelled with the same letter come from the same zone: S, Seggiano; AR, Arezzo; A, Lucca. Three levels corresponding to a different number of groups are marked.

olive oils (Mannina et al. 2001c) but not relevant within a European group. The results obtained applying this procedure are reported in literature (Mannina et al. 1999b, 2001a,b,c; Sacchi et al. 1996, 1998).

A very simple case, based on three Tuscany provinces, all around $100 \mathrm{Km}$ distance, will be discussed. The same olive variety is cultivated in two of these provinces, Lucca and Arezzo, while a moovarietal olive oil (cv. Seggianese) is produced in Seggiano, the third province. Several hierarchical clustering procedures based on the complete-linkage method with different distances were applied, and all the dendrograms gave the same result. Thus, Figure 11

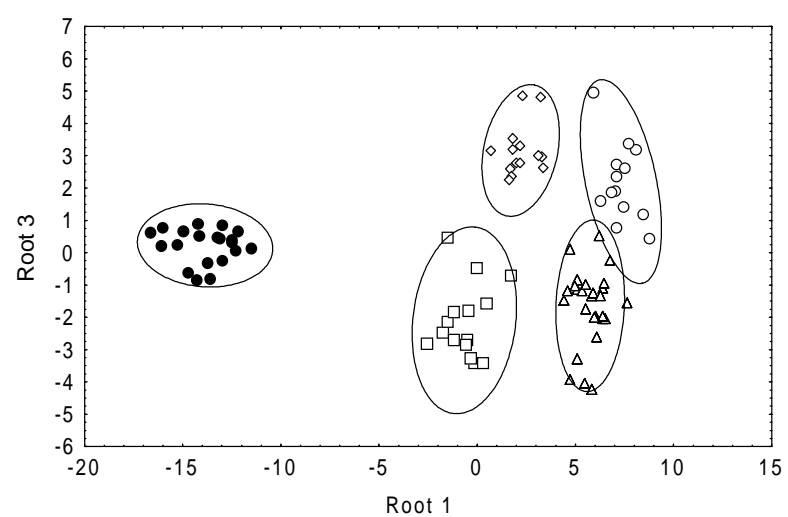

Figure 12

Linear discriminant analysis of extra virgin olive oils coming from Italian regions.

Note. $\bullet$, Garda; O, Tuscany-Arezzo; $\diamond$, Tuscany-Lucca; $\square$

Tuscany-Seggiano; $\Delta$, Lazio. Ellipses represent the $95 \%$ confidence regions for each group shows the dendrogram obtained by means of the Euclidean distance. It is interesting to observe that the branch with both different parameters, cultivar and territory, is fully separated from the other two sets, which differs only for their geographical origin. However, even those two sets are fully separated by a discriminant analysis procedure shown in Figure 11. We can conclude that both variables are present and they are additive. Hence, if particular cultivars are present in a particular environment we will get a strong effect with the result of a full separation. But if only the pedoclimatic variable is present we still are able to separate oils coming from different geographical regions, even if these regions are contiguous. On this regard, the NMR capability of distinguish oils on the basis of their geographical origin seems adequate.

Specific cultivars grown in the same district give rise to an oil recognizable at a lower level of distinction, see Figure11. In fact, all the olive oils grouped in the lowest level (A14, A13, A6, A5 and A10) belong to $\mathrm{cv}$. Quercetana.

On larger bases we have shown that ${ }^{1} \mathrm{H}$ NMR is able to distinguish olive oils from all over Italy regardless of the cultivars. A proper choice of selected resonances allows the geographical selection while other signals allow the cultivar selection (Mannina et al. 2001b), see Figure 12. Using the above criteria we are collecting a data basis for the geographical or the cultivar characterization even with olive oils from crops.

\section{AUTHENTICATION OF OLIVE OIL}

Figure $8 \mathrm{a}$ shows that ${ }^{13} \mathrm{C}$ resonances are indeed sensitive to the position of the fatty acid on the glycerol moiety. Therefore, NMR methods are a powerful way for determining not only the fatty acid composition but also their distribution on glycerol. Thus, any olive oil in which a palmitic residue is found in position 2 of the glycerol must be considered adulterated.

${ }^{1} \mathrm{H}$ NMR can hence be used to analyse oils of different botanical origin such as hazelnut oil and seed oils (Mannina et al. 1999c; Fauhl et al. 2000). NMR and GC can be used according to the following procedure, $\mathrm{n}$ order to evaluate the possibility of detecting the presence of hazelnut oil in olive oil samples. A comparison of the fatty acid composition of hazelnut oil versus the fatty acid composition of extra virgin olive oil; the linolenic acid content and volatile aldehydes present only in non-deodorized hazelnut oils can be easily detected with NMR. If the content of linolenic acid is lower than $0.5 \%$ or if anomalous aldehydes are present, GC analysis should be performed. Linear Discriminant Analysis (LDA) should be used to analyse the GC results. A 
combination of these two techniques would allow the determination of a possible adulteration of olive oil up to limits to can make the adulteration with hazelnut oil unprofitable, i.e., this method could allow to detect the addition of hazelnut oil at an extent of about $12 \%$.

We have shown that ${ }^{1} \mathrm{H}$ and ${ }^{13} \mathrm{C}$ NMR techniques allow characterizing olive oil. ${ }^{13} \mathrm{C}$ NMR can provide valuable information about the acyl distribution and the acyl positional distribution of glycerol tri-esters of different oils. ${ }^{1} \mathrm{H}$ NMR allows collecting information of minor olive oil components and the 1,2 and 1,3 acyl distribution. Furthermore, the ${ }^{1} \mathrm{H}$ NMR data allows the geographical characterization of Italian olive oils. All these results show that the Nuclear Magnetic Resonance can be useful in the olive oil characterization. However, it is important to underline that the proposed analyses with the NMR techniques are not official at present. However, we think that, due to the notorious advantages of ${ }^{13} \mathrm{C}$ and ${ }^{1} \mathrm{H}$ NMR techniques, their methodologies will become official for extra virgin olive oil analyses.

\section{NMR GLOSSARY}

Chemical shift, $\delta$. Chemical shift defines the position of a line on respect to that of a reference compound. For ${ }^{1} \mathrm{H}$ and ${ }^{13} \mathrm{C}$ the resonance of tetramethyl silane TMS is usually chosen and set to zero. $\delta$ is commonly expressed in ppm, being ppm $=$ (resonance $X$ in $\mathrm{Hz}$-resonance TMS in $\mathrm{Hz}$ )/carrier frequency in $\mathrm{Hz}$.

Coupling Constant, J. It characterizes scalar coupling occurring through chemical bonds. It is independent from the magnetic field. Typical values: ${ }^{13} \mathrm{C}-{ }^{1} \mathrm{H} \approx 150 \mathrm{~Hz} ;{ }^{13} \mathrm{C}-{ }^{13} \mathrm{C} \approx 35 \mathrm{~Hz}$ in $\mathrm{sp}^{3}$ systems; in double bonds ${ }^{1} \mathrm{HC}=\mathrm{C}^{1} \mathrm{H}$, cis $\approx 11 \mathrm{~Hz}$ and trans $\approx 16 \mathrm{~Hz}$; $\mathrm{HCH} \approx 1-2 \mathrm{~Hz}$; particularly useful the three bond coupling ${ }^{1} \mathrm{H}-\mathrm{C}-\mathrm{C}-{ }^{1} \mathrm{H} \approx 0-15 \mathrm{~Hz}$ depending from the $\cos ^{2} \theta$ of the dihedral angle; in aromatic rings ${ }^{1} \mathrm{H}-{ }^{1} \mathrm{H}$ ortho $\approx 8 \mathrm{~Hz} ;{ }^{1} \mathrm{H}-{ }^{1} \mathrm{H}$ meta $\approx 2-3 \mathrm{~Hz} ;{ }^{1} \mathrm{H}-{ }^{1} \mathrm{H}$ para $\approx 1 \mathrm{~Hz}$.

Relaxation mechanism. It constitutes an efficient way by which the excited system returns to its equilibrium value. In a magnetic field we can define transverse and longitudinal relaxation mechanisms leading to two values generally different. Transverse relaxation is usually called $\mathrm{T}_{2}$ or spin-spin relaxation. Longitudinal Relaxation is usually called $T_{1}$ or spin lattice relaxation. From relaxation times it is possible to deduce structural information and the dynamical properties of the system.

${ }^{13} \mathrm{C}$ satellites. In all organic compounds ${ }^{12} \mathrm{C}$, spin zero, is the most abundant carbon isotope. However, a small constant amount of ${ }^{13} \mathrm{C}$ isotope is always present having spin $1 / 2$ and a natural abundance about $1.108 \%$. The presence of a one bond coupling constant $(\approx 150 \mathrm{~Hz})$ causes a strong splitting of each ${ }^{1} \mathrm{H}$ line due to a proton bound to ${ }^{13} \mathrm{C}$ carbon atom originating the so called satellites lines which constitute a perfect internal standard.

$2 D$ experiment. Acronym indicating bi-dimensional NMR experiments. It represents an extension of the simple NMR spectroscopy in two frequency dimensions.

A 2D spectrum represents the function of a signal $F\left(\omega_{1}, \omega_{2}\right)$ of two independent variables. The basic scheme of whatsoever 2D experiment in the time domain is represented by at least four time intervals: $\tau_{\mathrm{p}}$ preparation, $\tau_{\mathrm{e}}$ evolution, $\tau_{\mathrm{m}}$ mixing, and $\tau_{\mathrm{a}}$ acquisition

According to the following temporal scheme: preparation - evolution- mixing- acquisition

The most common sequences are:

1. COSY, acronym of COrrelated SpectroscopY. COSY gives the connectivity between $\mathrm{J}$ coupled protons.

2. TOCSY, acronym of TOtal Correlated SpectroscopY. Similar to COSY, it is able to transfer the magnetization to all protons coupled to each other.

3. NOESY, Nuclear Overhauser Enhancement and Exchange SpectroscopY. It gives the connectivities between nuclei coupled through space.

4. INADEQUATE, Incredible Natural Abundance DoublE QUAntum Transfer Experiment; a sort of COSY between directly bound ${ }^{13} \mathrm{C}$ atoms.

Selective experiments. 1D analogs of 2D experiments. Only one resonance is excited, followed by the observation of those nuclei coupled ( $J$ or through space coupled) to the excited resonance.

\section{REFERENCES}

Alessandri, S., Cimato, A., Modi, G., Mattei, A., Crescenzi, A., Caselli S., Tracchi, S. (1997). Univariate models to classify Tuscan virgin olive oils by zone. Riv. Ital. Sostanze Grasse, 74, 155-163.

Aparicio, R. (1988). Characterizing Foods by Inexact Rules: SEXIA Expert System. J. Chemometrics, 3, 175-192.

Aparicio,.R., Alonso, M.V. (1994). Characterization of Virgin Olive Oils by SEXIA Expert Systems. Progress Lipid Res., 33, 29-38.

Aparicio, R., Alonso, V., Morales, M.T. (1994). Detailed and Exhaustive Study of the Authentication of European Virgin Olive Oils by SEXIA Expert System. Grasas Aceites, 45, 241-252.

Aparicio, R., Calvente, J.J., Morales, M.T. (1996). Sensory authentication of European extra-virgin olive oil varieties by mathematical procedures, J. Sci. Food Agric. 72, 435-439.

Balestrieri, F., Marini, D. (1996). Metodi di analisi chimica dei prodotti alimentari. Monolite: Roma, Italy,

Braun, S., Kalinowski, H.O., Berger S. (1998). 150 and More Basic NMR Experiments. Wiley.

Capitani, D., Segre, A.L., Sparapani, R., Scartazzini, R., Giustini, M., P.L. Luisi, P.L. (1991). Microemulsion 
Organogels from Lecithin: A NMR Study of Molecular Mobility based on line widths. Langmuir, 7, 250-253.

Croasmun, W.R., Carlson, M.K. (1994). Two-dimensional NMR spectroscopy; Applications for Chemists and Biochemists. VCH: New York.

Ernst, R.R., Bodenhausen, G., Wokaun, A., (1987) Principles of nuclear magnetic resonance in one and two dimensions. Clarendon Press, Oxford, G.B.

Fauhl, C., Reniero, F., Guillou, C. (2000). H NMR as a tool for the analysis of mixtures of virgin olive oils with oils of different botanical origin, Magn. Reson. Chem., 38, 436-443

Forina, M.; Tiscornia, E. (1982) Pattern recognition methods in the prediction of Italian olive oil origin by their fatty acid content. Ann. Chim., 72, 143-155.

Mannina, L., Luchinat, C., Emanuele, M.C., Segre, A.L. (1999a). Acyl positional distribution of glycerol tri-esters in vegetable oils: a ${ }^{13} \mathrm{C}$ NMR study. Chem. Phys. Lipids, 103, 47-55.

Mannina, L., Barone, P., Patumi, M., Fiordiponti, P., Emanuele, M.C., Segre A.L. (1999b). Cultivar and pedoclimatic effect in the discrimination of olive oils: A high-field NMR study. Recent Res. Devel. Oil Chem., 3, 85-92.

Mannina, L., Patumi, M., Fiordiponti, P., Emanuele, M.C., Segre, A.L (1999c). Olive and hazelnut oils: a study by high-field ${ }^{1} \mathrm{H}$ NMR and gas chromatography. Ital. $J$. Food. Sci. 11, 139-149.

Mannina, L., Luchinat, C., Patumi, M., Emanuele, M.C., Rossi, E., Segre, A.L. (2000). Concentration dependence of ${ }^{P 3} \mathrm{C}$ NMR spectra of triglycerides: implications for the NMR analysis of olive oils. Magn. Res. Chem., 38, 886-890.

Mannina, L., Patumi, M., Proietti, N., Segre, A.L. (2001a). D.O.P. (Denomination of Protected Origin) Geographical characterization of Tuscan extra virgin olive oil using high-field ${ }^{1} \mathrm{H}-\mathrm{NMR}$ spectroscopy. Ital. J. Food Sci., 13, 55-56.

Mannina, L., Patumi, M., Proietti, N., Bassi, D., Segre, A. L. (2001b). Geographical Characterization of Italian Extra Virgin Olive Oils Using High Field ${ }^{1} \mathrm{H}-\mathrm{NMR}$ Spectroscopy. J. Agric. Food. Chem., 49, 2687-2696.

Mannina, L., Fontanazza, G., Ansanelli, G., Segre, A.L. (2001c). Italian and Argentine olive oils: A NMR and gas-chromatographic study. Grasas Aceites, 52, 380-388.

Morales, M.T., Alonso, M.,V., Rios, J.J., Aparicio, R. (1995). Virgin Olive Oil Aroma: Relationship between Volatile Compounds and Sensory Attributes by Chemiometrics, J. Agric. Food Chem, 43, 2925-2931

Pogliani, L., Ceruti, M., Ricchiardi, G., Viterbo, D. (1994). An NMR and molecular mechanism study of squalene and squalene derivatives, Chem. Phys. Lipids, 70, 21-23.

Sacchi, R., Patumi, M., Fontanazza, G., Barone, P., Fiordiponti, P., Mannina, L., Rossi, E., Segre, A.L.' (1996). A high-field ${ }^{1} \mathrm{H}$ Nuclear Magnetic Resonance study of the minor components in virgin olive oils. $J$. Am. Oil Chem. Soc., 23, 747-758.

Sacchi R., Mannina, L., Fiordiponti, P., Barone, P., Paolillo, L., Patumi, M., Segre A.L. (1998). Geographical classjfication of Italian extra-virgin olive oils by high field $\mathrm{H}$-NMR spectroscopy. J. Agric. Food Chem., 46, 3947-3951.

Sanders J.K.M., Hunter B.K. (1993). Modern NMR Spectroscopy. Oxford Univ. Press: Oxford U.K.

Segre, A.L., Mannina, L. (1997). 'H-NMR study of edible oils. Recent Res. Devel. in Oil Chem., 1, 297-308.

Tsimidou M., Macrae R.; Wilson I. (1987). Authentication of virgin olive oils using principal components analysis of triglyceride and fatty acid profiles: part 1. Classification of Greek olive oils. Food Chem. 25, 227-239. 